\title{
Editorial
}

\section{The Garnett Passe and Rodney Williams Memorial Foundation}

This Foundation was established by the late Mrs Barbara Williams of Charleston, South Carolina to honour the memory of her two husbands, Garnett Passe and Rodney Williams, and is one of the largest bequests ever made to Australian medicine.

Garnett Passe although an Australian, qualified and practised Otorhinolaryngology most successfully in London. Although he died of hypertension in 1952 at the age of 48 years, he had by this time acquired an enviable reputation as a superb practitioner of the fenestration operation and a pioneer of surgery of the sympathetic system, for conditions such as Menière's disease. He frequently spoke at the Royal Society of Medicine and it was the wish of his widow, who died in the very house where Garnett Passe had practised, that a lecture should be inaugurated in the memory of her husband at that institution.

Largely due to the untiring efforts of the two Trustees, the late Colin Richards and the present Chairman Peter Freeman (both eminent Antipodean Otologists), this biennial lecture has now been established. A selection panel comprising the Presidents of the Otology and Laryngology \& Rhinology Sections of the RSM, President of the American Academy of ORL-Head and Neck Surgery, Secretary of the Collegium and the Chairman of the Trustees, with the Chief Executive of the RSM as Secretary was established, and the first lecturer appointed in 1995. A Coat of Arms has been agreed by Garter King of Arms, which incorporates the Spirit of the Foundation combined with items relating to the two individuals whose memory is to be honoured. The lecturer receives a medal which incorporates these Arms and a generous Honorarium.

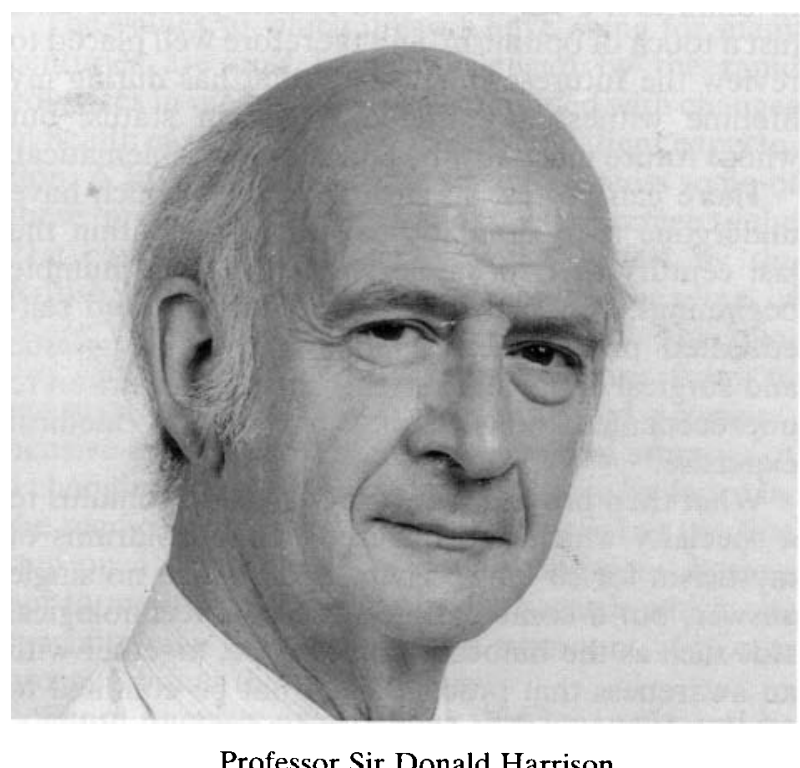

The first Garnett Passe and Rodney Williams Memorial lecture was delivered by Professor Sir Donald Harrison, Emeritus Professor of Otolaryngology, University of London and President of the Royal Society of Medicine, on 3 May 1996 at the Royal Society of Medicine. The lecture is printed in its entirety in the following pages.

DONALD HARRISON 